\title{
QUALITATIVE STUDY OF AIRFLOW STRUCTURE ACROSS WOODEN LOUVRED WINDOW PANELS FOR NATURAL VENTILATION APPLICATIONS
}

\begin{abstract}
Nur Baitul Izati Rasli
$\mathrm{PhD}$ degree in the fields of Indoor Air Quality and Thermal Comfort from Universiti Sains Malaysia. Research Assistant, School of Civil Engineering, Universiti Sains Malaysia. Nibong Tebal, (Malaysia).

E-mail: nurbaitulizati@gmail.com ORCID: https://orcid.org/0000-0001-5454-8539
\end{abstract}

\begin{abstract}
Nor Azam Ramli
PhD degree in Environmental Engineering from University of Wales, United Kingdom. Professor, School of Civil Engineering, Universiti Sains Malaysia. Nibong Tebal, (Malaysia). E-mail: ceazam@usm.my ORCID: https://orcid.org/0000-0001-6328-0183
\end{abstract}

\begin{abstract}
Mohd Rodzi Ismail
PhD degree in Building Engineering from University of Liverpool, United Kingdom. Associate Professor, School of Housing, Building and Planning, Universiti Sains Malaysia. Minden, (Malaysia). E-mail: rodzi@usm.my ORCID: https://orcid.org/0000-0002-1020-5398
\end{abstract}

Noorfazreena Mohammad Kamaruddin

$\mathrm{PhD}$ degree in Aerospace Engineering from University of Manchester, United Kingdom. Senior Lecturer, School of Aerospace Engineering. Nibong Tebal, (Malaysia). E-mail: fazreena@usm.my ORCID: https://orcid.org/0000-0002-5897-8728

Recepción: 25/05/2021 Aceptación: 04/08/2021 Publicación: 14/09/2021

\section{Citación sugerida:}

Rasli, N. B. I., Ramli, N. A., Ismail, M. R., y Kamaruddin, N. M. (2021). Qualitative study of airflow structure across wooden louvred window panels for natural ventilation applications. 3C Tecnología. Glosas de innovación aplicadas a la pyme, 10(3), 73-99. https://doi.org/10.17993/3ctecno/2021.v10n3e39.73-99 


\section{ABSTRACT}

Window ventilation usually used in energy-efficient buildings as an effective natural ventilation system to provide an adequate opening for fresh air to flow into the interior space. It could help to reduce the indoor air temperature and limit the contaminants in buildings. This study aimed to visualise the airflow structure across a wooden louvred window panel using the smoke flow visualisation technique at different airflow speeds of $0.5,1.0,2.0,3.0$ and $5.0 \mathrm{~m} / \mathrm{s}$ in a closed-loop wind tunnel. Two Sony 1920 $\times 1080$ i cameras captured the airflow structure, which took the side view, rear view, front view and back view images. The wooden louvred window panel promotes optimum outdoor airflow and facilitates continuous air exchange to replace the indoor air. Results showed that smoke filled the space quickly at the highest airflow speed of $5 \mathrm{~m} / \mathrm{s}$. This study used an inclination angle of $75^{\circ}$ for the wooden louvred window panel to avoid rain splatter. Besides, wood material could be used as a façade shading device. Therefore, installing the wooden louvred window panels could enhance natural ventilation, ensure indoor thermal comfort and reduce indoor air contaminants.

\section{KEYWORDS}

Passive Design, Natural Ventilation, Airflow Structure, Indoor Air Quality, Thermal Comfort, Sustainable Development. 


\section{INTRODUCTION}

Malaysia is a tropical country that experiences a hot and humid climate throughout the year. It is near the equator, whereas approximately one-third of the world population experiences hot-dry or warm and humid climates (Jamaludin et al., 2015; Laurini et al., 2017). High humidity and temperature levels increase the risk of thermal discomfort and moisture problems in indoor settings (Hamimah et al., 2010). A study by Jamaludin et al. (2015) found that the indoor air temperatures of a residential building in Malaysia at different microclimates exceed the acceptable limit of thermal comfort suggested in the Malaysian Standard (MS 1525:2007) $\left(23^{\circ} \mathrm{C}-26{ }^{\circ} \mathrm{C}\right)$, with the highest indoor temperature being $32.6{ }^{\circ} \mathrm{C}$ under the Kuala Lumpur climate.

In response to the effects of high indoor thermal conditions, people install air-conditioning systems in their indoor environment for cooling purposes (Jamaludin et al., 2015). The practice may increase the energy demand and energy cost of residential and commercial buildings and thereby challenge the sustainable cities' effort (Jamaludin et al., 2015; Kubota \& Toe, 2015; Kassim et al., 2016; Cui et al., 2017; Laurini et al., 2017). Modern technology recirculates the indoor air instead of refreshing it, contributing to poor indoor air quality (Spiru \& Simona, 2017). Moreover, air conditioning usage adds to the imperfect removal of indoor air contaminants (Cui et al., 2017), including carbon monoxide, carbon dioxide, formaldehyde and biological contaminants (Kaunelien et al., 2016; Li et al., 2017; Cheung \& Jim, 2019). Indoor air quality needs to be maintained within acceptable limits as it can affect human health (Sun et al., 2015; de Robles \& Kramer, 2017; Steinemann et al., 2017; Amoatey et al., 2018; Krawczyk \& Wadolowska, 2018).

As a solution to this problem, the wind from outside can be used as natural ventilation to eliminate the need for air-conditioning systems. A natural ventilation system is a passive design strategy for buildings, applied for cost-effective electricity consumption and fossil fuel usage (Allocca et al., 2003; Gratia \& De Herde, 2007; Ahmed \& Wongpanyathaworn, 2012; Zhong et al. 2012; Aflaki et al., 2014). The adoption of such systems is aimed at achieving sustainable development goals and is ideal as they do not incur 
any energy cost (Kassim et al., 2016). Fresh air is fundamentally required in the interior spaces to provide enough oxygen for breathing, reduce excessive heat, limit indoor air contaminants, decrease $\mathrm{CO}_{2}$ concentrations and dilute and remove odours (Bayoumi, 2017).

In natural ventilation, fresh outside air is induced naturally by the temperature and pressure differences between spaces to replace the indoor air continuously through openings (vents, windows, doors and so forth) (Bangalee et al., 2014). Natural ventilation can either be wind-driven natural ventilation (cross ventilation) or buoyancy-driven natural ventilation (stack ventilation); the former attributed to pressure differences generated by the wind while the latter is caused by buoyancy forces (Mohammadmirzaei, 2018). Cross and stack ventilation may also co-occur, in which wind and stack effects could reinforce or oppose one another (Allocca et al., 2003). Figure 1 illustrates the cross and stack ventilation in a building. Cross ventilation supplies and extracts the air flowing in the same building level that passes through vertical openings, whereas stack ventilation concerns the upper and lower openings (Ohba \& Lun, 2011).

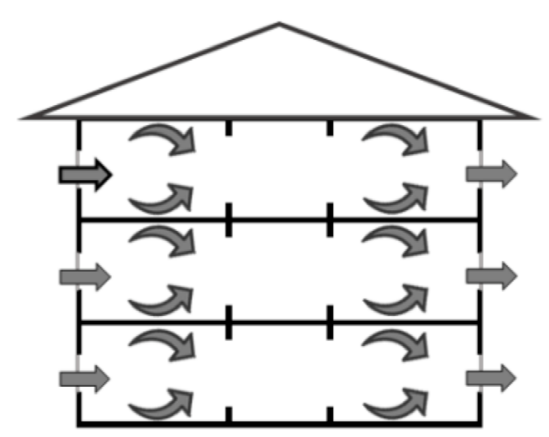

(a)

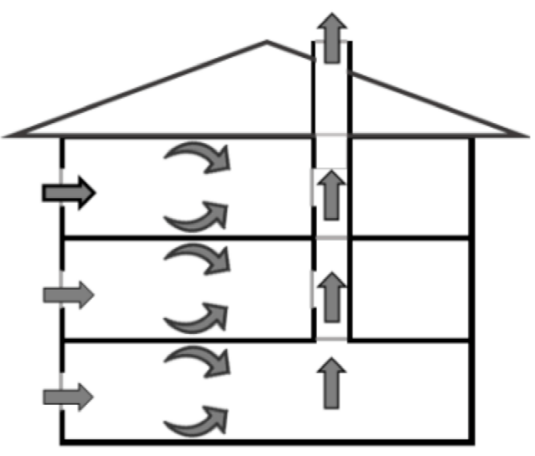

(b)

Figure 1. (a) Cross ventilation and (b) stack ventilation.

Source: (Ohba \& Lun, 2011).

Besides, the opening location can enhance the effectiveness of natural ventilation through cross ventilation. For single-sided walls, leeward walls are better opening locations than the windward walls (Ma et al., 2017). Extensive recirculation is produced at the centre of the building with single-sided walls. 
The direction of airflow in windward ventilation is anticlockwise as opposed to leeward ventilation, and it is more robust due to the vortices behind the buildings. Kassim et al. (2016) reported that the best opening location is at the upper part of the windward façade as it allows a large amount of air to penetrate a building; however, the ventilation rate decreases as the opening position shifts towards the lower part of the building façade.

The current study is conducted to develop and improve the previous research by Rasli et al. (2019) by applying a wooden louvred window panel to enhance the outdoor air inflow. In that study, Rasli et al. (2019) visualised the airflow structure of outdoor air that permeates through the window panels with apertures using the smoke flow visualisation technique in a wind tunnel laboratory. The results suggested that double apertures with a $2.4 \%$ opening on window panels could promote optimum outdoor airflow indoors relative to single apertures $(1.2 \%)$ and no aperture $(0 \%)$. Double apertures also provide security by which windows be kept closed for $24 \mathrm{~h}$.

Hence, this wind tunnel study's objective is to visualise the airflow structure across the wooden louvred window panel using the smoke generator technique at different airflow speeds of 0.5, 1.0, 2.0, 3.0 and $5.0 \mathrm{~m} / \mathrm{s}$. The proposed wooden louvred window panel can also provide protection from the rain splatter while allowing the air outside to come inside. Besides, wood material could be used as a façade shading system, in which due to its hygroscopic properties, it could be advantageous for occupants as it could lead to decreasing in energy cost, enhance energy efficiency and improve indoor comfort in buildings (Vailati et al., 2018; El-Dabaa et al., 2020). When wood is applied, it gives a passive motion technique stimulated by the variation of relative humidity which can be ideal in a tropical climate.

\subsection{LOUVRED WINDOWS}

Generally, louvres are apertures with angled slots either horizontally or vertically that permit air and light to pass through but at the same time block direct sunlight, rain and noise from penetrating the interior areas. Accordingly, a louvred window consists of integrated angled slats within a frame to perform such 
functions. For this study, a louvred window with horizontal slats was used. The effectiveness of airflow permeating through a louvred window is controlled by the input, geometry and output variables, as shown in Figure 2.

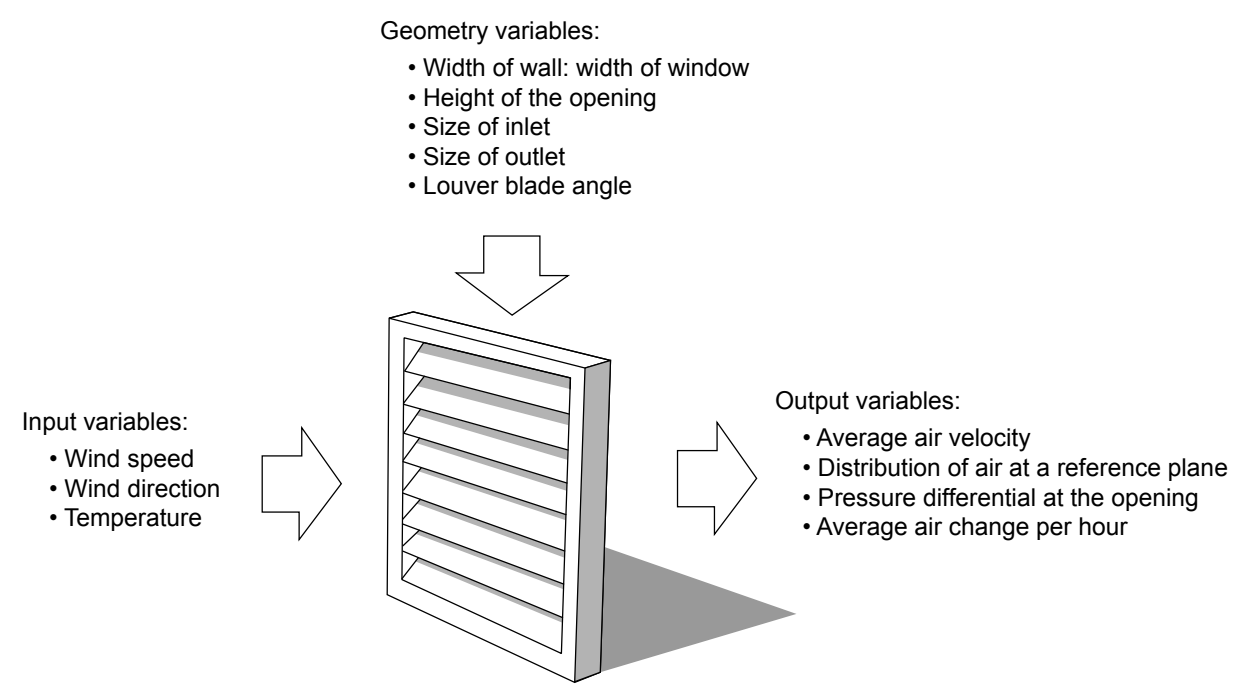

Figure 2. Variables that affect the airflow through a louvred window.

Source: (Chandrashekaran, 2010).

\subsection{WIND TUNNEL}

The experiment of smoke flow visualisation can be performed to visualise the airflow structure in and around the test model by using the illumination of smoke filaments in the test section of a wind tunnel. The use of wind tunnel experiment on the natural ventilation study was adopted in several works (Ohba et al., 2001; Karava et al., 2007; Ghu et al. 2009; Chu et al. 2010; Ji et al., 2011), while Elmualim (2006), Montazeri \& Azizian (2009), Chandrashekaran (2010) and Esfeh et al. (2012) have included the smoke visualisation test in their natural ventilation studies using wind tunnels. 
The airflow in a wind tunnel has three different characteristics depending on the condition: laminar flow (i.e. streamline flow), transitional flow (i.e. between laminar and turbulent flow) and turbulent flow (i.e. chaotic flow) (Chandrashekaran, 2010). In laminar flow, the air moves in parallel at low velocities caused by the viscous air forces. In transitional flow, some of the air moves in parallel whilst some disperses. In turbulent flow, air moves at high velocities, and pressure varies irregularly in time and position. The Reynolds number $(\mathrm{Re})$ characterises the airflow characteristics, in which the airflow may be laminar, transitional or turbulent when the Re is below 2,000, between 2,000 and 4,000 and more than 4,000, respectively (Figure 3).

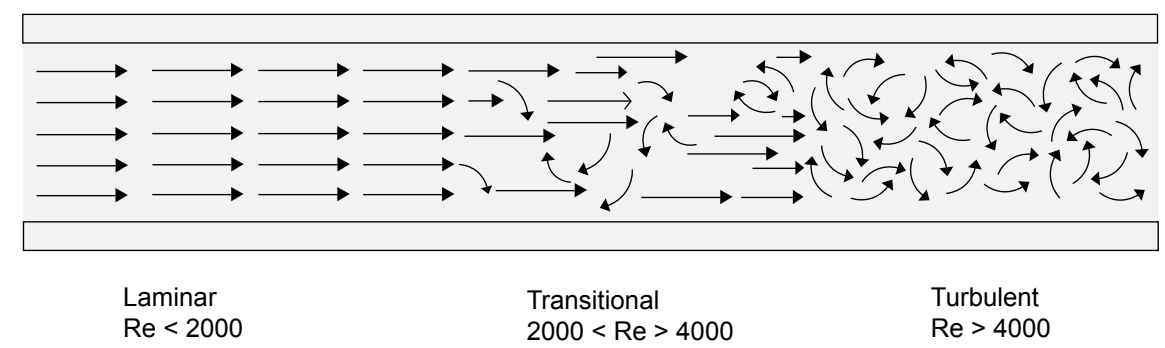

Figure 3. Characteristics of laminar, transitional and turbulent airflow.

Source: (Chandrashekaran, 2010).

\section{MATERIALS AND METHODS}

The ventilation openings of louvred windows from vernacular architecture techniques could improve cross-ventilation by increasing the indoor air pressure. They promote the outdoor airflow towards indoors to lower indoor air temperature and reduce indoor air contaminants. The variables used in this study for the model testing are the airflow speeds (i.e. 0.5, 1.0, 2.0, 3.0 and $5.0 \mathrm{~m} / \mathrm{s}$ ). The resulting airflow characteristics are subsequently analysed. 


\subsection{DIMENSIONS OF WOODEN LOUVRED WINDOW PANEL MODEL}

The louvred window used in this work was made of wood and had a smooth finish. The dimension of the slotted-up wooden louvred window panel was $36 \mathrm{~cm}$ (width) $\times 57 \mathrm{~cm}$ (height), inserted at the centre of a clear acrylic measuring $90 \mathrm{~cm}$ (width) $\times 60 \mathrm{~cm}$ (height), which served as the window base. A wooden frame holder measuring $100 \mathrm{~cm}$ (width) $\times 80 \mathrm{~cm}$ (height) was used to hold the wooden louvred window panel in a vertical position in the middle of the test section (Figure 4).

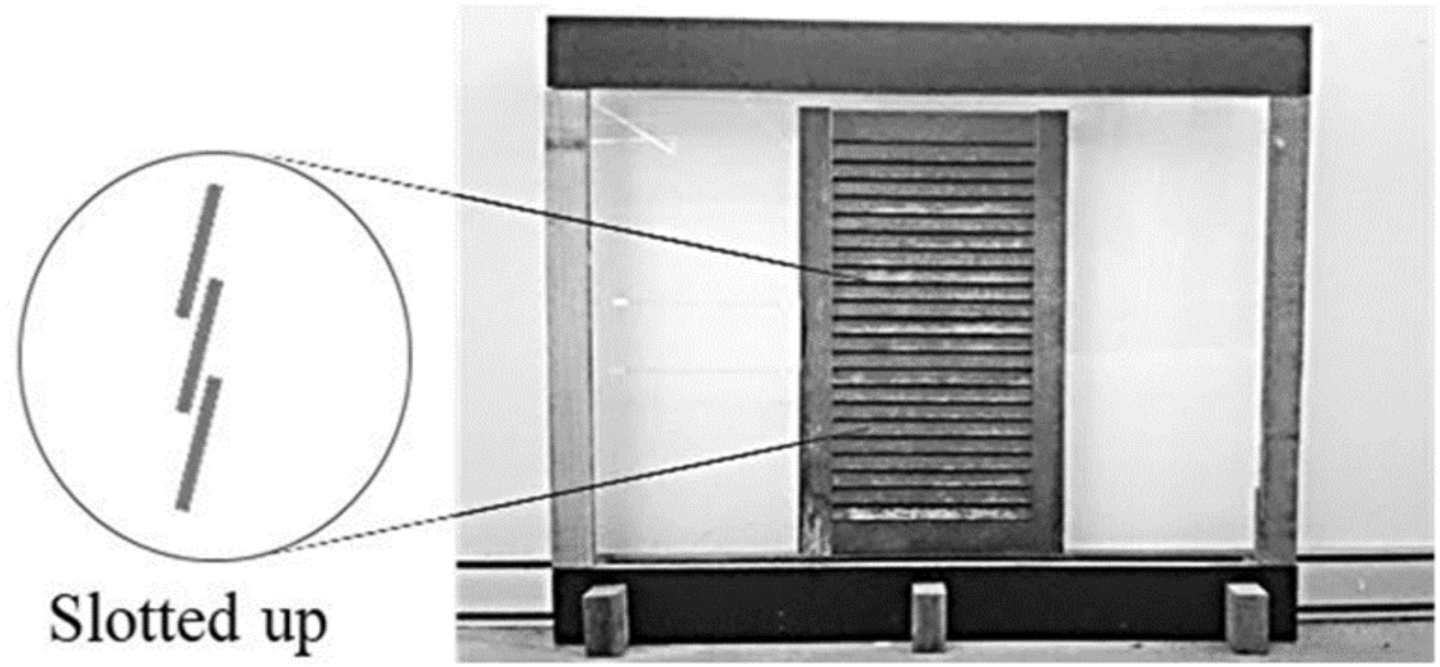

Figure 4. Configuration of the wooden louvred window panel.

Source: own elaboration.

\subsection{THE ANGLE OF THE WOODEN LOUVRED WINDOW PANEL MODEL}

Studies on the relationship between the louvre angles and natural ventilation performance were conducted by various researchers (Yakubu \& Sharples, 1991; Hughes \& Ghani, 2010; Chandrashekaran, 2010; Lee et al., 2016). This study focused on a wooden louvred window panel model with 22 slots inclined at $75^{\circ}$, 
in which the gap between each slot was $2 \mathrm{~cm}$ (Figure 5). The free area's opening between the slots had a vital function as it influenced the velocity and pressure differences across the wooden louvred window.

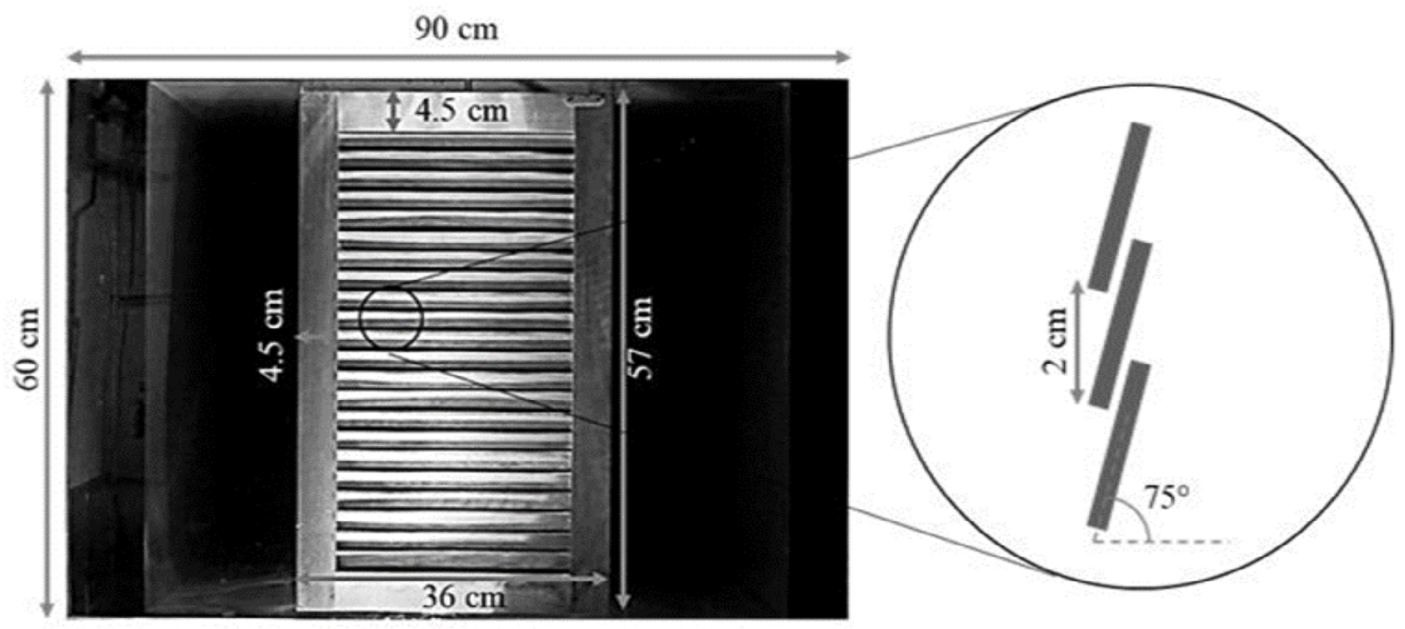

Figure 5. Dimension of the wooden louvred window panel with the slot's gap size and angle.

Source: own elaboration.

\subsection{CLOSED-CIRCUIT WIND TUNNEL}

The smoke flow visualisation testing was carried out at the Wind Tunnel Laboratory, Science and Engineering Research Centre, Universiti Sains Malaysia. The closed-loop wind tunnel measuring $2,052.6 \mathrm{~cm}($ length $) \times 818.8 \mathrm{~cm}($ width $) \times 350.0 \mathrm{~cm}$ (height) produces an airstream for the study of the effects of airflow moving in and around the wooden louvred window panel model. The model was then placed in the test section between the settling chamber and the wind tunnel diffuser. The wind tunnel had a rectangular test section measuring $1 \mathrm{~m}$ (width) $\times 0.80 \mathrm{~m}$ (height) $\times 1.80 \mathrm{~m}$ (length), a contraction ratio of 10:1 and a turbulence level of $0.1 \%$ for the flow speed of up to $80 \mathrm{~m} / \mathrm{s}$. The axial fan, with the aid of the diffuser downstream in the test section, drove the airflow to the test section. The airflow speeds were controlled using the wind tunnel's control panel and were verified using a hot wire anemometer. 


\subsection{SMOKE FLOW VISUALISATION TECHNIQUE}

The testing for smoke flow visualisation was conducted using the smoke generator technique to evaluate the airflow structure of the wooden louvred window panel model at different airflow speeds as illustrated in Figure 6. The wooden louvred window panel was placed at the centre of the wind tunnel test section while the smoke sources (smoke generator) were positioned vertically at $25 \mathrm{~cm}$ from the wooden window panel's midsection. The optimal distance contributed significantly to the best-illustrated streamlines of the smoke, which represented the airflow structure. The smoke generator was at the top of the wind tunnel test section while the smoke rake was positioned inside the test section.

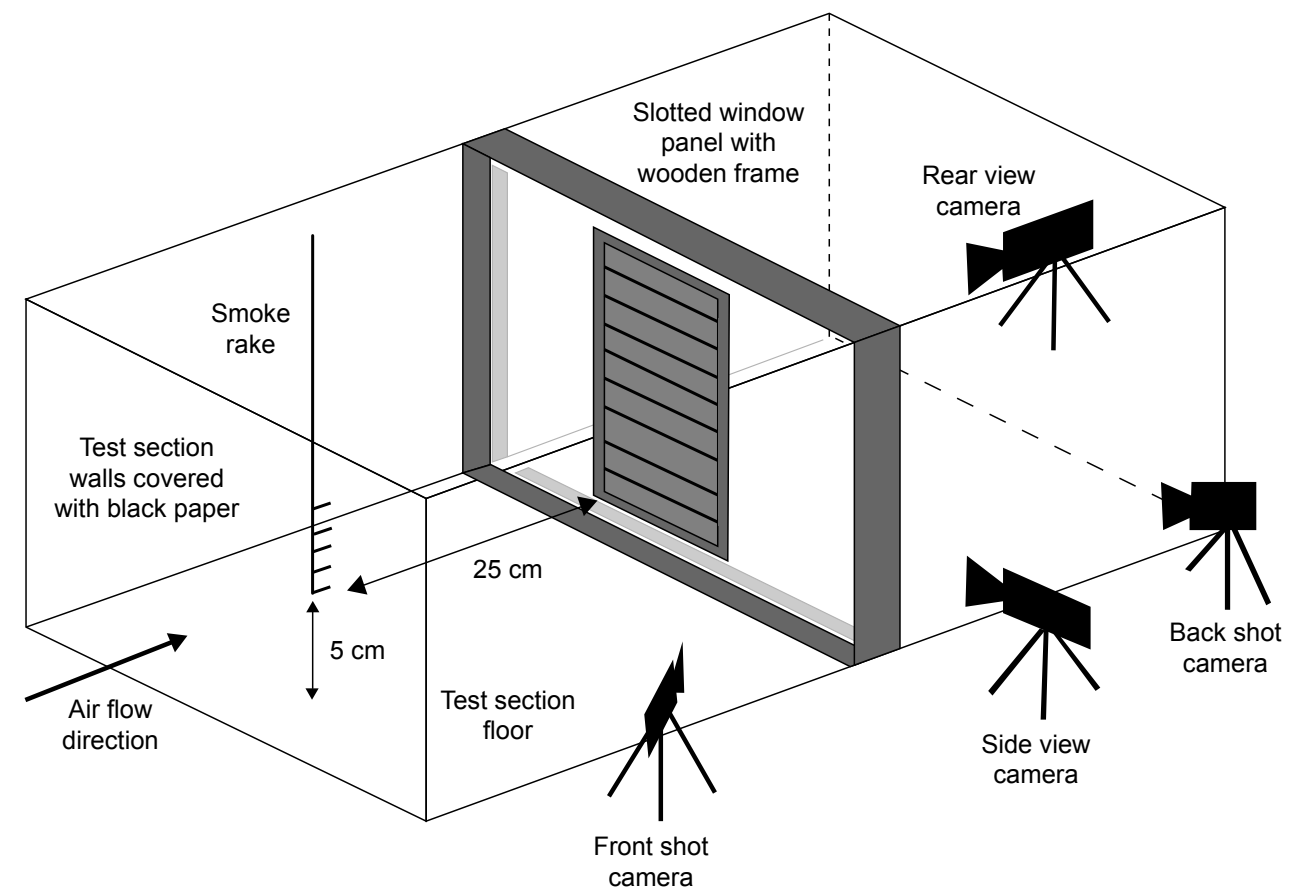

Figure 6. Illustration of wooden louvred window panel using the smoke generator technique at five different airflow speeds of 0.5 , $1.0,2.0,3.0$ and $5.0 \mathrm{~m} / \mathrm{s}$ and different camera positions (i.e. side view, rear view, front view and back view) inside the wind tunnel test section.

Source: own elaboration. 
In the smoke generator flow visualisation technique, a smoke generator (SAFEX Fog Generator FOG 2010 by Dantec Dynamics) produces smoke particles at a rate of approximately $600 \mathrm{~m}^{3} / \mathrm{min}$. The smoke intensity was controlled using a handheld remote control with a rotary knob scaled at number 5 for a favourable amount $\left(600 \mathrm{~m}^{3}\right)$ of smoke. The setup of the smoke generator is shown in Figure 7 . The generated smoke particles were pumped through the smoke rake located at the inlet of the test section. Meanwhile, a flexible delivery tube was used to connect the smoke generator to the smoke rake.

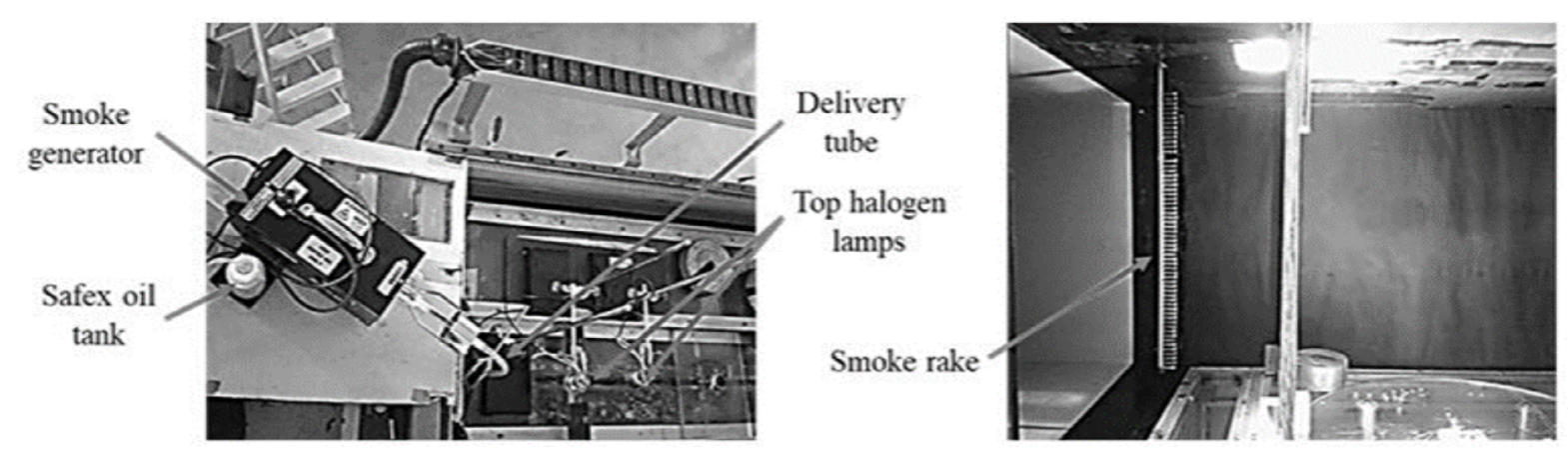

Figure 7. Flow visualisation setup using the smoke generator technique on the top and inside the wind tunnel test section.

Source: own elaboration.

Two Sony $1920 \times 1080 \mathrm{i}$ cameras were mounted outside at the centre (side view) and inside (rear view) of the test section to record the airflow structure. The testing was repeated with both cameras mounted outside and positioned at the front and backside to capture these areas' flow structure. The test section's inner wall was installed with a black paper cover to minimise any reflection that could affect the results and to increase the clarity of the streamlines. Two white halogen light bulbs installed on top and at the bottom of the test section illuminated the smoke flow structure released from the smoke rake.

\section{RESULTS}

The wooden louvred window panel introduced in this study was aimed at promoting the optimum flow of fresh outdoor air into indoor spaces for passive ventilation and enhancing natural ventilation towards 
the development of sustainable buildings. Improved indoor air quality and thermal discomfort can be achieved (i.e. decrease the space's temperature) by increasing the natural ventilation area (Noman et al., 2016; Lei et al., 2017). Thus, the objective is to solve thermal comfort issues and improve air quality in indoor spaces (Ocak et al., 2012; Hameed \& Habeeballah 2013; Alananbeh 2017; Yu et al., 2017; Nahar \& Mahyudin 2018; Rasli et al., 2019; Azuma et al., 2020).

The side view, rear view, front view and back view images obtained in the wind tunnel testing are shown in Figures 8-12. Specifically, the figures show the airflow structure across the wooden louvred window panel based on the smoke generator technique at five different airflow speeds. The smoke streamlines from the smoke generator in the wind tunnel represented the outdoor airflow structure toward the indoor space.

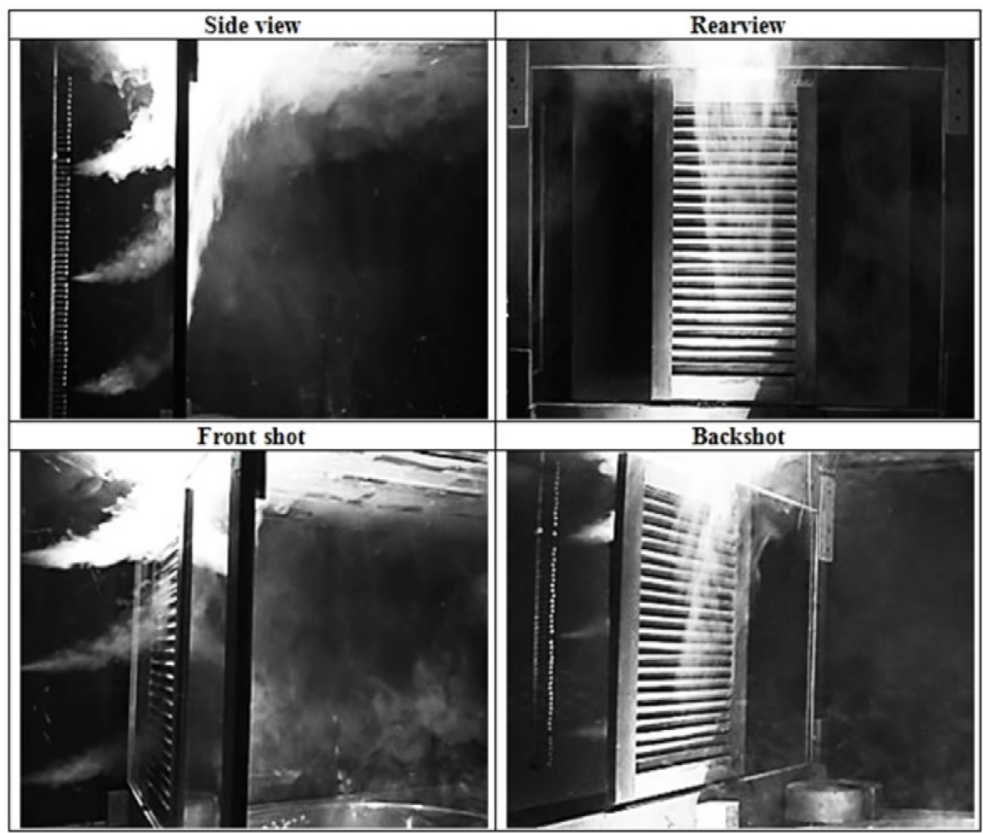

Figure 8. Visualised airflow structure across the tested wooden louvred window panel using the smoke generator technique at $0.5 \mathrm{~m} / \mathrm{s}$ inside the wind tunnel test section.

Source: own elaboration. 


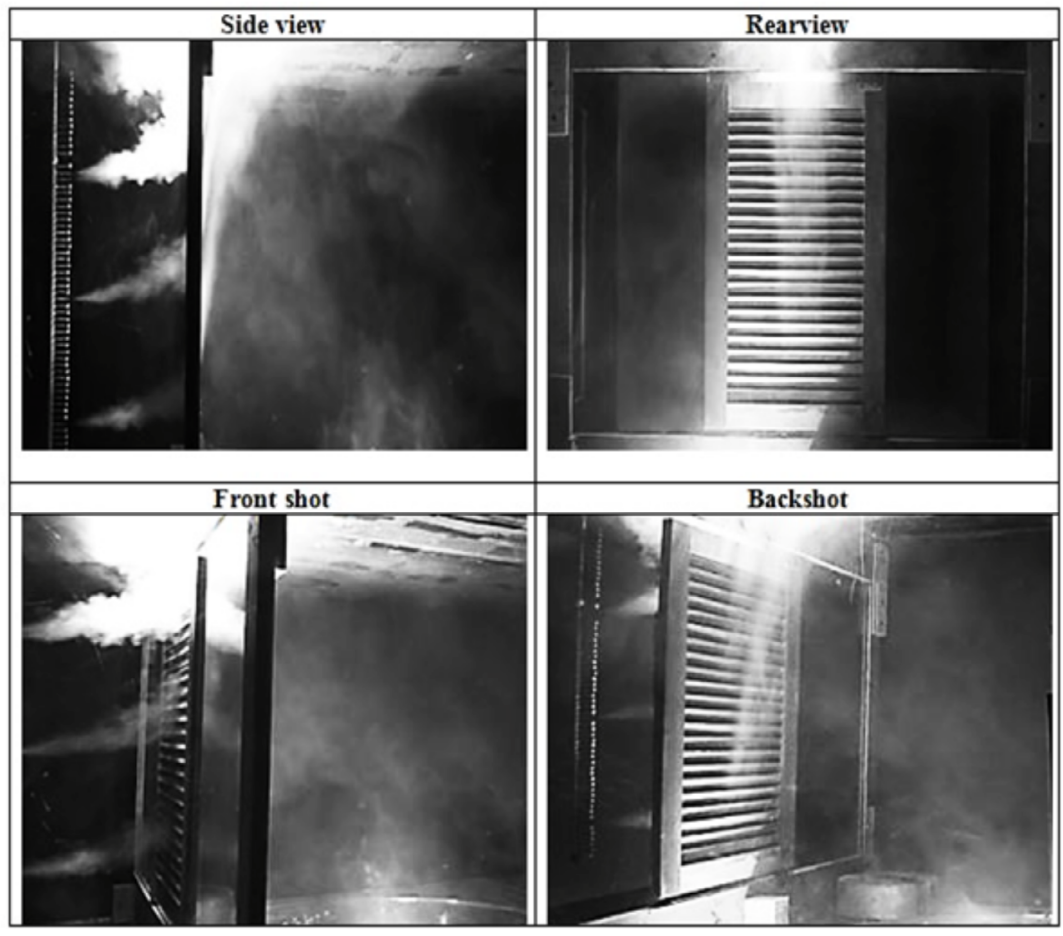

Figure 9. Visualised airflow structure across the tested wooden louvred window panel using the smoke generator technique at $1.0 \mathrm{~m} / \mathrm{s}$ inside the wind tunnel test section.

Source: own elaboration. 


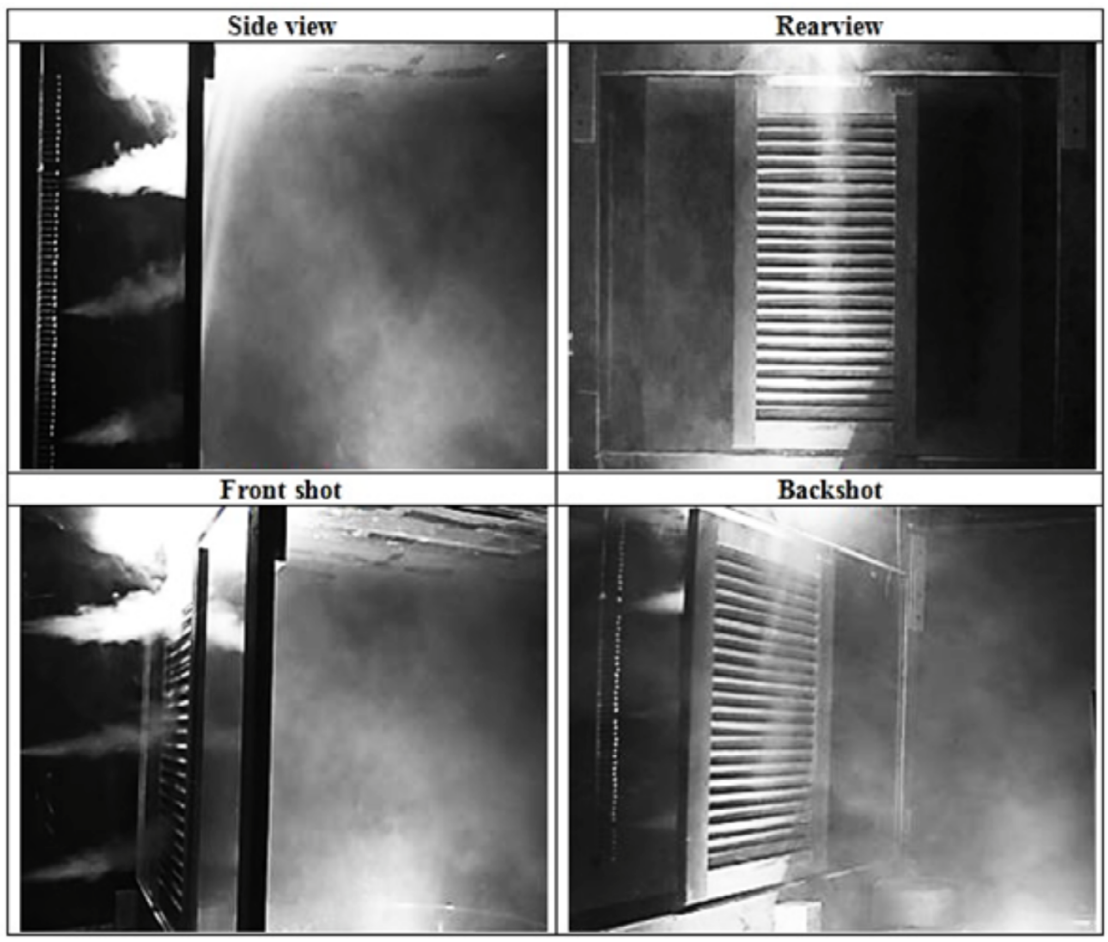

Figure 10. Visualised airflow structure across the tested wooden louvred window panel using the smoke generator technique at $2.0 \mathrm{~m} / \mathrm{s}$ inside the wind tunnel test section.

Source: own elaboration. 


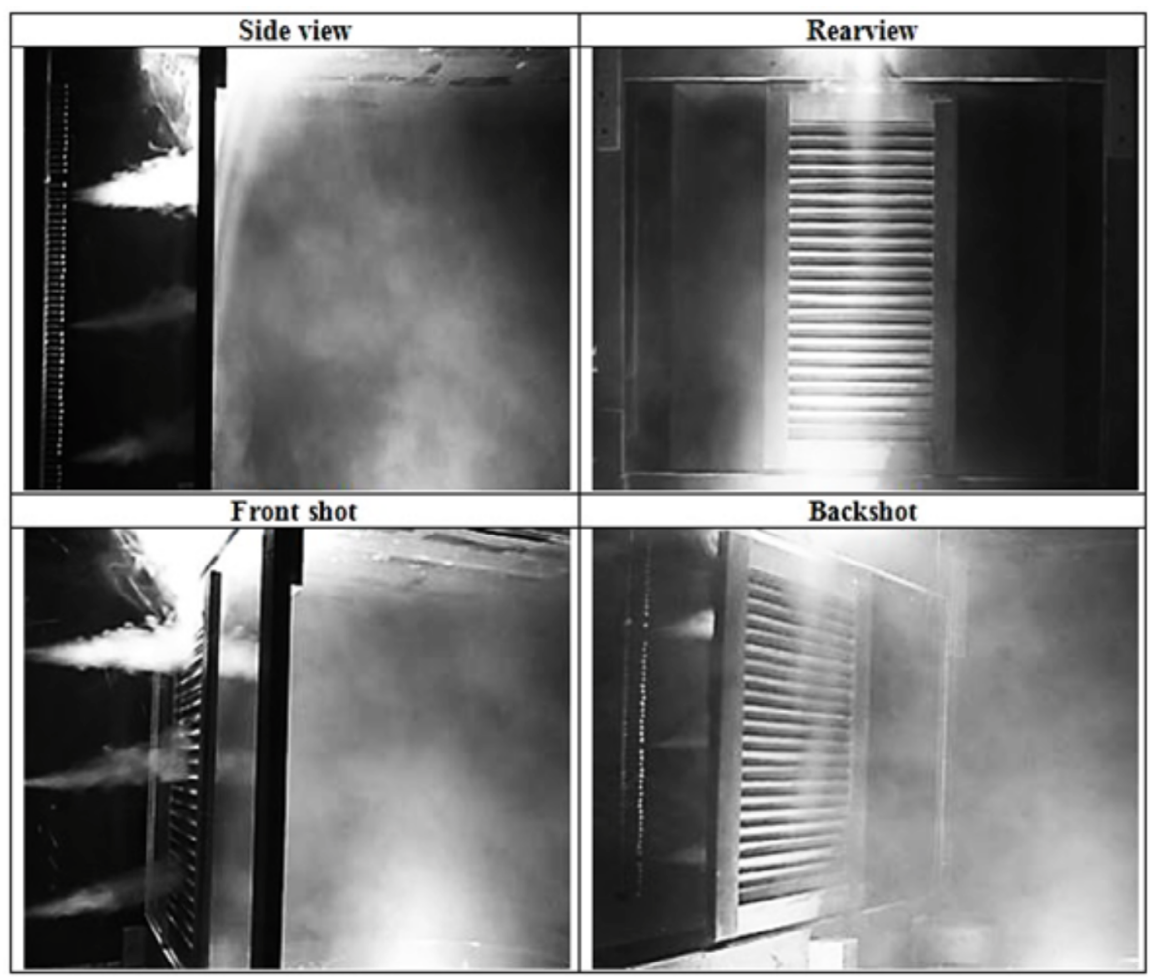

Figure 11. Visualised airflow structure across the tested wooden louvred window panel using the smoke generator technique at $3.0 \mathrm{~m} / \mathrm{s}$ inside the wind tunnel test section.

\section{Source: own elaboration.}




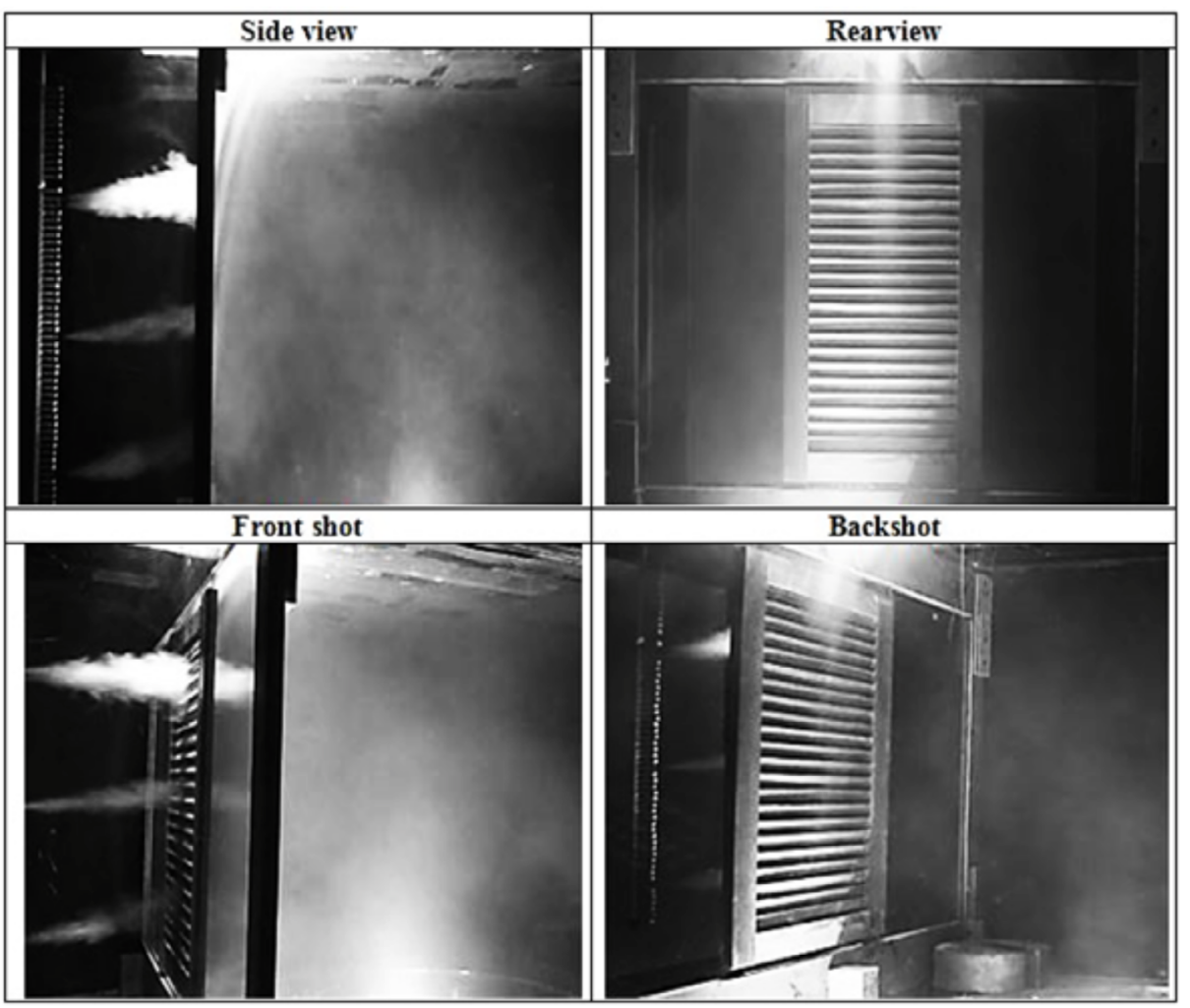

Figure 12. Visualised airflow structure across the tested wooden louvred window panel using the smoke generator technique at $5.0 \mathrm{~m} / \mathrm{s}$ inside the wind tunnel test section.

Source: own elaboration.

In Figure 8, at $0.5 \mathrm{~m} / \mathrm{s}$, the airflow had quite a sharp upward curve pattern; it reached the louvres, then continued to concentrate towards the upper part of the space as it passed through the louvres, upon which the airflow spread slowly to the other amount of the space. A similar pattern could be seen for the speed of airflow at $1.0 \mathrm{~m} / \mathrm{s}$ in Figure 9. However, less upward curve pattern of airflow was observed between the smoke rake and the wooden louvred window panel, and the airflow seemed to be spread faster to the other part of the space. At $2.0 \mathrm{~m} / \mathrm{s}$ (Figure 10), a much lesser upward curve of airflow could 
be noticed before it entered the space and most of the airflow seemed to spread to the other part of the space as little concentration of airflow to the upper part of the space could be observed. Figure 11 shows that at $3.0 \mathrm{~m} / \mathrm{s}$, there was still some airflow that moves upwards after crossing the louvres even though simultaneously the airflow spread to the other part of the space. At $5.0 \mathrm{~m} / \mathrm{s}$, as shown in Figure 12, the upward movement of airflow after crossing the louvred panel was almost unnoticeable as the airflow spread quickly throughout the space. Also observed that at lower airflow speeds of 0.5, 1.0, 2.0 and 3.0 $\mathrm{m} / \mathrm{s}$, some air at the upper part of the wooden louvred panel did not pass through the louvre slots.

The airflow structure from outdoors to indoors could contribute to the cross and stack ventilation within an indoor space of a building. According to Malaysian Standard (MS 1525:2014) ("MS 2014. Malaysian Standard. MS 1525", 2014), cross ventilation functions by enhancing airflow structure flow through a building caused by a wind-generated pressure drop across it. The warmer air within the building is discharged through the opposite louvred window opening while the cooler outside air enters the building and continuously replaces the warmer air.

Meanwhile, stack ventilation functions by enhancing the flow of airflow structure across space due to air density differences. The warmer air at the upper levels is discharged through the opening near the ceiling. Then, the cooler outside air enters the building through the lower opening (door or window). Stack ventilation is more advantageous in reducing energy than mechanical and air conditioning (Lomas, 2007).

Louvre angle plays a vital role in determining airflow volume and direction into indoor spaces (Aflaki $e t$ al., 2015). Chandrashekaran (2010) reported that the volume of airflow passing through indoor spaces is affected by louvre opening angles of $0^{\circ}, 15^{\circ}$ and $30^{\circ}$ and that the direction of airflow is affected by a louvre opening angle of $45^{\circ}$. Louvred openings are also the best ventilation for night-time flushing in a tropical climate as they could increase force ventilation (Kubota et al., 2009). A perpendicular louvre window is recommended for natural ventilation systems to increase the pressure inside buildings (Sahabuddin, 2012). 
The results herein indicated that the wooden louvred window panel could continuously replace the indoor air with outdoor air to improve natural ventilation. The proposed panel eliminates the need to open doors and windows for $24 \mathrm{~h}$, thereby offering security. Rasli et al. (2019) proposed apertures on window panels to increase the maximum amount of fresh outdoor air moving towards indoor spaces and thereby lower the indoor temperatures and realise proper natural ventilation. The continuation of natural ventilation is vital to reduce the indoor air contaminants that may remain present for years because it aids in diluting the outdoor air that enters buildings (Moreau-Guigon et al., 2016).

At a low airflow speed, the airflow was observed to permeate the window panel slowly, and the airflow structure at the leeward side of the window panel was circulating and broad. As the airflow speed increased, the airflow permeated the wooden louvred window panel extremely fast, and the airflow structure at the leeward side straightened and showed small air motions. The results showed that an increase in airflow speed contributed to the high airflow velocity passing through the wooden window panel and that the airflow filled the indoor space quickly. Ji et al. (2018) found that the flow rate of smoke mass increases with the elevated ambient pressure because of the increase in air density and enhanced air entrainment. By contrast, the rate of smoke mass flow decreases with the reduction in ambient pressure, air density and air entrainment, and the heat gain within a building reduced with an increase in air velocity (Sunakorn \& Yimprayoon, 2011). With maximum airflow facilitating the air exchange, it can enhance adequate natural ventilation for improved thermal comfort and indoor air quality.

The wooden louvred window panel can protect against the rain splatter. An inclination angle of $75^{\circ}$ of the wooden window panel models can help prevent rain splatter from entering the indoor space. As mentioned by Recatala et al. (2018), the characteristics of the materials used, the geometry of the external cladding element and the edge profile of joints influence the degree of water tightness of the ventilated façades. This combination can avoid the dampness problem, which causes microbial growth. Rasli et al. (2019) reported that microbial growth is strongly dependent on the indoor temperature and 
relative humidity; thus, indoor air quality needs to be maintained at the suggested acceptable limit to protect users from health risks.

\section{CONCLUSIONS}

Air-conditioning systems typically installed to overcome problems in indoor thermal comfort. However, the systems' air recirculation could contribute to poor indoor air quality and high energy demand and energy cost. Hence, this study aimed to visualise the airflow structure from the outdoors to indoor spaces by using the smoke flow visualisation technique (i.e. smoke generator technique) in a wind tunnel laboratory. The proposed wooden louvred window panel was tested using the smoke generator technique at different airflow speeds of 0.5, 1.0, 2.0, 3.0 and $5.0 \mathrm{~m} / \mathrm{s}$. Two Sony $1920 \times 1080 \mathrm{i}$ cameras were used to capture the side view, rear view, front view and back view images of the airflow structure. The use of wooden louvred window panels improves natural ventilation because it promotes lateral movement of fresh outdoor air continuously. At the highest airflow speed $(5 \mathrm{~m} / \mathrm{s})$, the proposed wooden louvred window panel can contribute to the optimum replacement of indoor air with outdoor airflow and increase the air exchange rate. The inclination angle of $75^{\circ}$ of the wooden louvred window panel can help avoid the rain splatter, and the wood material can be used for façade shading purposes. This work could help address the problems of thermal comfort and indoor air quality and facilitate the development of sustainable buildings. There is also a limitation in this study in which the window panel was not tested for different slot angles, which could determine the best angle for the optimum outdoor air due to the high cost of wind tunnel testing.

\section{ACKNOWLEDGMENT}

The Universiti Sains Malaysia supported this work under BRIDGING GRANT(304/PAWAM/6316537). Special thanks to Mr Badrul and Mr Tarek for their contribution to this work. 


\section{REFERENCES}

Aflaki, A., Mahyuddin, N., Awad, Z.A.C.M., \& Baharum, M.R. (2014). Relevant indoor ventilation by windows and apertures in a tropical climate, a review study. In E3S Web of Conferences 3 (01025). EDP Sciences. https://doi.org/10.1051/e3sconf/20140301025

Aflaki, A., Mahyuddin, N., Awad, Z.A.G.M., \& Baharum, M.R. (2015). A review of natural ventilation applications through building façade components and ventilation openings in tropical climates. Energy and Buildings, 101, 153-162. https://doi.org/10.1016/j.enbuild.2015.04.033

Ahmed, N.A., \& Wongpanyathaworn, K. (2012). Optimising louvre location to improve indoor thermal comfort based on natural ventilation. Procedia Engineering, 49, 169-178. https://doi. org/10.1016/j.proeng.2012.10.125

Alananbeh, K.M., Boquellah, N., Al Kaff, N., \& Al Ahmadi, M. (2017). Evaluation of aerial microbial pollutants in Al-Haram Al-Nabawi during pilgrimage of 2013. Saudi fournal of Biological Sciences, 24, 217-225. https://doi.org/10.1016/j.sjbs.2015.08.003

Allocca, C., Ghen, Q., \& Glicksman, L.R. (2003). Design analysis of single-sided natural ventilation. Energy and Buildings, 35(8), 785-795. https://engineering:purdue.edu/ yanchen/paper/2003-11. pdf

Amoatey, P., Omidvarborna, H., Baawain, M.S., \& Al-Mamun, A. (2018). Indoor air pollution and exposure assessment of the gulf cooperation council countries, a critical review. Environment International, 121, 491-506. https://doi.org/10.1016/j.envint.2018.09.043

Azuma, K., Jinno, H., Tanaka-Kagawa, T., \& Sakai, S. (2020). Risk assessment concepts and approaches for indoor air chemicals in Japan. International Fournal of Hygiene and Environmental Health, 225, 1-9. https://doi.org/10.1016/j.ijheh.2020.113470 
Bangalee, M.Z.I., Miau,J.J., Lin, S.Y., \& Ferdows, M. (2014). Effects of lateral window position and wind direction on wind-driven natural cross ventilation of a building, a computational approach. Journal of Computational Engineering, 2014, 1-15. https://doi.org/10.1155/2014/310358

Bayoumi, M. (2017). Impacts of window opening grade on improving the energy efficiency of a façade in hot climates. Building and Environment, 119, 31-43. https: / /doi.org/10.1016/j.buildenv.2017.04.008

Chandrashekaran, D. (2010). Air Flow Through Louvered Openings, Effect of Louver Slats on Air Movement Inside a Space. University of Southern California, California, United States, 141.

Gheung, P.K., \& Jim, G.Y. (2019). Indoor air quality in substandard housing in Hong Kong. Sustainable Cities and Society, 48, 1-10. https://doi.org/10.1016/j.scs.2019.101583

Ghu, G.R., Ghiu, Y.H., Ghen, Y-J., Wang, Y-W., \& Chou, G.P. (2009). Turbulence effects on the discharge coefficient and mean flow rate of wind-driven cross-ventilation. Building and Environment, 44(10), 2064-2072. https://doi.org/10.1016/j.buildenv.2009.02.012

Chu, G.R., \& Wang, Y-W. (2010). The loss factors of building openings for wind-driven ventilation. Building and Environment, 45(10), 2273-2279. https://doi.org/10.1016/j.buildenv.2010.04.010

Gui, X., Mohan, B., Islam, M.R., Ghou, S.K., \& Chua, K.J. (2017). Energy saving potential of an air treatment system for improved building indoor air quality in Singapore. Energy Procedia, 143, 283-288. https://doi.org/10.1016/j.egypro.2017.12.685

Robles, D. de, \& Kramer, S.W. (2017). Improving indoor air quality through the use of ultraviolet technology in commercial buildings. Procedia Engineering, 196, 888-894. https://doi.org/10.1016/j. proeng.2017.08.021

El-Dabaa, R., Abdelmohsen, S., \& Mansour, Y. (2020). Programmable passive actuation for adaptive building façade design using hygroscopic properties of wood. Wood Material Science \&̊ Engineering, 16(4), 246-259. https://doi.org/10.1080/17480272.2020.1713885 